\title{
Programa Jovem Aprendiz: a interdisciplinaridade na formação teórica do programa
}

\author{
Morgada Ferreira dos Santos, Jerônimo Sartori \\ ${ }^{1}$ Bacharel em Ciências Contábeis - URCAMP, Graduanda em Pedagogia - UFSM, Pós-graduada em \\ Educação: Interdisciplinaridade e Transversalidade - UNIPAMPA. E-mail: morgadasantos@hotmail.com. \\ 2 Doutor em Educação pelo PPGEdu/Faced/UFRGS. Professor da UFFS, Campus Erechim. \\ jetori55@yaho.com.br.
}

\begin{abstract}
Resumo
A presente investigação, realizada nos anos de 2014 e 2015, baseou-se em estudo de caso, em que foram analisados os materiais didáticos do Programa Jovem Aprendiz e as respostas dadas a um questionário aplicado aos jovens matriculados no programa. Teve por principal objetivo verificar se no Programa Jovem Aprendiz são abordados os temas transversais, e se ocorre a interdisciplinaridade no desenvolvimento dos conteúdos durante a aprendizagem teórica dos jovens. Buscou-se, também, analisar a forma como a interdisciplinaridade, quando verificada e adotada no curso de aprendizagem, motiva o jovem, auxiliando-o na transposição das barreiras vivenciadas ao longo da sua formação no curso. Destacamos que o programa visa colaborar com a inserção do jovem no mundo do trabalho, baseado na Lei $n^{\circ}$ 10.097/2000, ampliada pelo Decreto Federal no 5.598/2005, em que o jovem recebe profissionalização durante as atividades teóricas e práticas, desenvolvidas, respectivamente, na unidade de capacitação teórica e na empresa res ponsável pela sua formação profissional.
\end{abstract}

Palavras-chave: Jovem aprendiz. Profissionalização. Trabalho. Interdisciplinaridade. Transversalidade.

Abstract

The following investigation, carried out in the years of 2014 and 2015, was based on a case study, in which were analyzed the didatic materials of the Programa Jovem Aprendiz ${ }^{1}$ and the answers given to a questionaire applied on the younglings enrolled on the program. It's main objective was to verify if the transversal themes were approached during the Programa Jovem Aprendiz, and whether interdisciplinarity was used in the development of the subjects during the younglings' theoretical learning. We also looked for an analysis of how interdisciplinarity, when verified and adopted on the course, motivates the youth, helping them on transposing the barriers experienced during their formation. We highlight that the program sees to collaborate with the youth's insertion into the work force, based on Law $n^{0}$ 10.097/2000, augmented by Federal Act $n^{-0}$ 5.598/2005, in which the youth receives profissionalization during the theoretical and practical activities, developed, respectively, in the theoretical capacitation unity and the company responsible for their professional formation.

Keyword: Young apprentice. Profissionalization. Work. Interdisciplinarity. Transversality. 


\section{Introdução}

Todo o estudo acerca dos processos formativos demanda atenção ao contexto em que estamos inseridos. No que refere à formação para o ingresso no mundo do trabalho, é necessário atentar para as demandas do mercado, contudo, sem ignorar as matrizes que orientam o horizonte capitalista. Este cuidado é necessário para não perder de vista que formamos humanos, não construímos máquinas: educamos homens que conquistam a superação sem serem descartados como artefatos obsoletos. O ser humano precisa ser visto em sua integridade física e moral, não como um objeto descartável e programável.

Ao estudar o Programa Jovem Aprendiz, fundamentalmente, é necessário considerar que a formação para o mundo do trabalho precisa ultrapassar a dimensão do pragmatismo, do apenas "saber fazer". Todas as ações desenvolvidas nos processos formativos devem ancorar-se em bases epistemológicas que orientem a visão de homem, de trabalho e de mundo. Ao ter como principal objetivo a garantia ao jovem da experiência necessária e do conhecimento teórico-prático indispensável para desempenhar uma profissão com competência e habilidade, o Programa Jovem Aprendiz não pode abrir mão de orientar esses jovens para o exercício consciente de sua cidadania com capacidade de sentir-se sujeito.

O Programa Jovem Aprendiz possui duração de até 24 meses e tem por principal objetivo a inclusão de jovens, com idade entre 14 a 24 anos incompletos, ao mundo do trabalho. Por meio do programa, esses jovens têm a oportunidade de se desenvolverem pessoal e profissionalmente, adquirindo conhecimentos que terão significativa importância para sua inserção no mundo do trabalho. Tais conhecimentos dão ao jovem uma oportunidade de estarem mais qualificados e aptos a aspirarem por uma vaga no concorrido campo profissional. Neste programa, o jovem tem a oportunidade de aprender trabalhando, desse modo, vai se inserindo no mundo do trabalho, tendo uma formação teórica que é exigida nas diversas áreas profissionais.

A Lei 10.907, de 19 de dezembro de 2000, alterada por medida provisória em 2005, que modifica alguns dispositivos das Leis do Trabalho (CLT), diz que:

Contrato de aprendizagem é o contrato de trabalho especial, ajustado por escrito e por prazo determinado, em que o empregador se compromete a assegurar ao maior de 14 anos e menor de 24 anos, inscrito em programa de aprendizagem, formação técnico-profissional metódica, compatível com o seu desenvolvimento físico, moral e psicológico, e o aprendiz, a executar, com zelo e diligência, as tarefas necessárias a essa formação.

A presente pesquisa foi realizada por intermédio de estudo de caso desenvolvido em duas unidades de capacitação teórica do Programa Jovem Aprendiz, ambas sem fins lucrativos, localizadas na cidade de São Gabriel/RS. Cabe-nos destacar que o estudo justificou-se pela necessidade de conhecer qual foi a forma utilizada no Programa Jovem Aprendiz, em face da possibilidade de abordar os Temas Transversais e a Interdisciplinaridade nesse processo formativo. Destacamos que o programa atinge jovens de diversos níveis de escolaridade, desde o ensino fundamental até o ensino superior, tendo como prioridade a assistência aos jovens oriundos de famílias carentes e/ou em situação de 
vulnerabilidade social, salienta-se também que suas instrutoras possuem formação superior nas áreas de Pedagogia e Administração.

Neste estudo, ao problematizar a questão dos jovens aprendizes, procuramos entender como eles chegam ao curso de aprendizagem, quais as suas dificuldades e como procuram superar tais dificuldades para ingressar no mundo do trabalho. Abordamos, também, a forma como esse estudo foi desenvolvido, os seus resultados e as discussões pertinentes realizadas durante o mesmo, quais os temas transversais estudados durante o curso pelos jovens aprendizes, procurando entender como ocorre a interdisciplinaridade no processo de formação do programa em pauta.

\section{Metodologia}

Partindo das competências observadas no material didático do curso, o presente estudo considera que o conhecimento não ocorre somente no âmbito escolar ou acadêmico dos jovens, mas que as práticas educativas e interdisciplinares são vivenciadas também no cotidiano dessas pessoas e no ambiente de trabalho, no qual desempenham sua profissão, utilizando-se dos conhecimentos adquiridos em diversas disciplinas. Ou seja, é a teoria sendo vivenciada na prática diária, portanto, proporcionando aos jovens a oportunidade de adquirir conhecimentos que poderão fazer sobressair a sua vida profissional.

O Programa Jovem Aprendiz, tendo como objetivo contribuir com a formação educativa voltada ao trabalho dos jovens, possibilita complementar os conteúdos vistos em sala de aula, tanto do ensino fundamental quanto do ensino médio, técnico e superior, tornando o jovem sujeito ativo da sua própria aprendizagem. O curso de formação, nesse programa, favorece o aprofundamento teórico articulado aos saberes produzidos e vivenciados na empresa onde se realiza a prática profissional.

Ressaltamos que durante os meses de agosto de 2014 até julho de 2015, observamos como ocorriam os encontros de aprendizagem nas unidades formadoras, investigamos se eram estudados os Temas Transversais, bem como se havia práticas interdisciplinares no programa. Ao mesmo tempo, buscamos analisar se o material didático das instituições formadoras indicava as competências desejadas para a formação complementar dos jovens em formação.

No mês de julho de 2015, foi realizada uma pesquisa com 28 jovens das duas instituições, através da aplicação de questionários individuais e anônimos. A intenção do questionário foi de identificar o público jovem matriculado no programa, buscando saber se os mesmos possuíam conhecimentos sobre os temas transversais e a interdisciplinaridade, bem como, para conhecer a identificação social do jovem.

\section{Discussão dos achados no estudo}

Por intermédio desta pesquisa, observamos quais são temas transversais abordados na formação teórica desses jovens aprendizes, e se ocorre a interdisciplinaridade, se esta está evidenciada ou não no material didático e nos aspectos práticos das unidades teóricas.

No que diz respeito ao tópico 'temas transversais', são tratados conteúdos que não serão, obrigatoriamente, estudados dentro do currículo escolar formal, mas são temas relevantes e da atualidade, que necessitam ser abordados pela escola, como forma de complemento aos conteúdos 
vinculados às disciplinas de conhecimentos específicos. Então, os temas transversais constituem-se em possibilidades de abordar conceitos e valores fundamentais à democracia e à cidadania, ou seja, tratar de aspectos essenciais para a formação humana, sob várias questões relativas à vida cotidiana.

O enfoque interdisciplinar favorece a articulação entre conhecimentos de distintos campos do saber, o que torna possível a superação das práticas disciplinares fragmentadas. Nesse sentido, Bonatto (2012, p. 2) lembra que "A interdisciplinaridade é um elo entre o entendimento das disciplinas nas suas mais variadas áreas. Sendo importante, pois, abrangem temáticas e conteúdos, permitindo dessa forma recursos inovadores e dinâmicos, onde as aprendizagens são ampliadas".

Falar sobre interdisciplinaridade significa explorar as disciplinas de forma unificada como um elo, uma união, que torna um determinado assunto capaz de ser tratado por vieses que integram áreas diversas do conhecimento. Por exemplo, o tema Meio Ambiente pode ser abordado, estudado e tratado numa aula de Matemática, tendo a colaboração do professor de Arte, de Geografia, entre outros.

\subsection{Dos temas transversais abordados no programa de aprendizagem}

Segundo os PCN's (1998, p. 65), os temas transversais que compõem os Parâmetros Curriculares Nacionais são Ética, Saúde, Meio Ambiente, Pluralidade Cultural, Orientação Sexual e Trabalho e Consumo; eles envolvem problemáticas sociais da atualidade, consideradas de abrangência nacional e, até mesmo, mundial. São indicações amplas e que se traduzem em preocupações em todo o país, haja vista que são questões polissêmicas no âmbito da sociedade, gerando dissensos e confrontos de opiniões. Contudo, elas necessitam de abordagens com base no conhecimento socialmente produzido.

Essa abrangência não significa que os temas transversais devam ser tratados igualmente em todos os lugares. Ou seja, a transversalidade deve ter um olhar vinculado à realidade dos sujeitos que interagem em determinado espaço social; portanto, esses temas podem exigir adaptações para que correspondam às reais necessidades de cada região ou mesmo de cada escola.

Mucida et al (2012, p. 2) complementam o entendimento sobre os objetivos dos Temas Transversais e sua articulação com a perspectiva da Interdisciplinaridade e/ou da Transversalidade:

[...] De acordo com os PCN's, os Temas Transversais tem o objetivo de proporcionar a inserção de questões sociais à estrutura curricular, implicando uma metodologia de ensino interdisciplinar e preocupada em respeitar a faixa etária de cada aluno. A junção da transversalidade e interdisciplinaridade desenvolverá nos alunos habilidades de aprendizagem condizentes com sua realidade.

Conforme estudo exploratório em livros, apostilas e demais materiais utilizados durante o curso de formação destes jovens, observamos que os temas transversais estão inseridos no cotidiano de estudos dos mesmos. Logo, a abordagem desses temas é de grande valia para que os jovens aprendizes formem-se cidadãos comprometidos com uma sociedade mais justa e digna, tendo respeito e dedicação ao próximo e com as empresas em que atuarão como futuros profissionais.

Com relação aos temas transversais, conforme já citado, o curso aborda as diversas temáticas, por meio dos seguintes temas: Tecnologias da Informação e Comunicação, Empreendedorismo, Segurança do Trabalho e Legislação Trabalhista, Ideologia, Moral e Ética, Preconceito, Drogas e 
Educação Ambiental. Nesses temas, os jovens trabalham em grupos, realizam pesquisas, constroem conhecimentos sobre as temáticas abordadas, considerando os benefícios que isso possa lhes trazer, tanto para a vida pessoal como para a vida social e no mundo do trabalho.

De acordo com Hamze (2015), os temas transversais representam campos exitosos para organizar práticas interdisciplinares, integrando com as áreas do conhecimento temas que tenham evidência prática na vida real, social e comunitária dos sujeitos. Por conseguinte, é de suma importância que os jovens tenham, durante sua formação teórica, a possibilidade de compartilhar com seus pares, bem como com as instrutoras de aprendizagem, os conhecimentos que possuem sobre os temas transversais, como utilizam esses temas no seu cotidiano. E, também, tenham a oportunidade de refletir sobre como esses temas podem colaborar com sua inserção no mundo do trabalho, tornando-os sujeitos críticos acerca da realidade em que estão e/ou serão inseridos.

Nesse encadeamento, refere Figueiró (2000, p. 01) que:

Os "temas transversais" dizem respeito a conteúdos de caráter social, que devem ser incluídos no currículo do ensino fundamental, de forma "transversal", ou seja: não como uma área de conhecimentos específica, mas como conteúdo a ser ministrado no interior das várias áreas estabelecidas.

A educação é considerada um aspecto prático e ativo, que toma parte da convivência social. Desse modo, cabe-nos realçar que na sociedade todos educam a todos e em todos os espaços. Como o indivíduo não vive isolado, sua educação é contínua (PINTO, 1982). É através da educação, com a finalidade de formar para o trabalho, que o conhecimento adquirido diariamente facilita ao indivíduo a transposição das barreiras que o separam do progresso profissional e do mundo do trabalho.

Para Demo (2011, p. 16):

[...] conhecimento é processo diário, como a própria educação, que não começa nem acaba...conhecer faz parte do conceito de vida criativa [...]. Assim, pode-se dizer que é através desses conhecimentos adquiridos diariamente que os jovens terão a oportunidade de buscar uma melhor qualificação de vida, de ser humano, de formação profissional.

Segundo os PCN's, é fundamental que a educação esteja comprometida com a cidadania, trabalhando junto aos alunos, os princípios da dignidade da pessoa, da igualdade de direitos, da participação e corresponsabilidade pela vida social. A Lei Federal no 9.394/96, em seu art. 27, inciso I, também destaca que os conteúdos curriculares da educação básica deverão observar "a difusão de valores fundamentais ao interesse social, aos direitos e deveres dos cidadãos, de respeito ao bem comum e à ordem democrática".

Se a aprendizagem for bem sucedida, o aluno constrói uma representação de si mesmo como alguém capaz de aprender (PCN's, 1998). Para que esta aprendizagem possa acontecer de maneira significativa, é necessário que o jovem tenha interesse em transpor suas dificuldades em relação à sua 
própria aprendizagem, superando obstáculos que dificultam seu progresso no desempenho escolar. A seguir, a figura com o esquema dos temas transversais estudados no Programa Jovem Aprendiz:

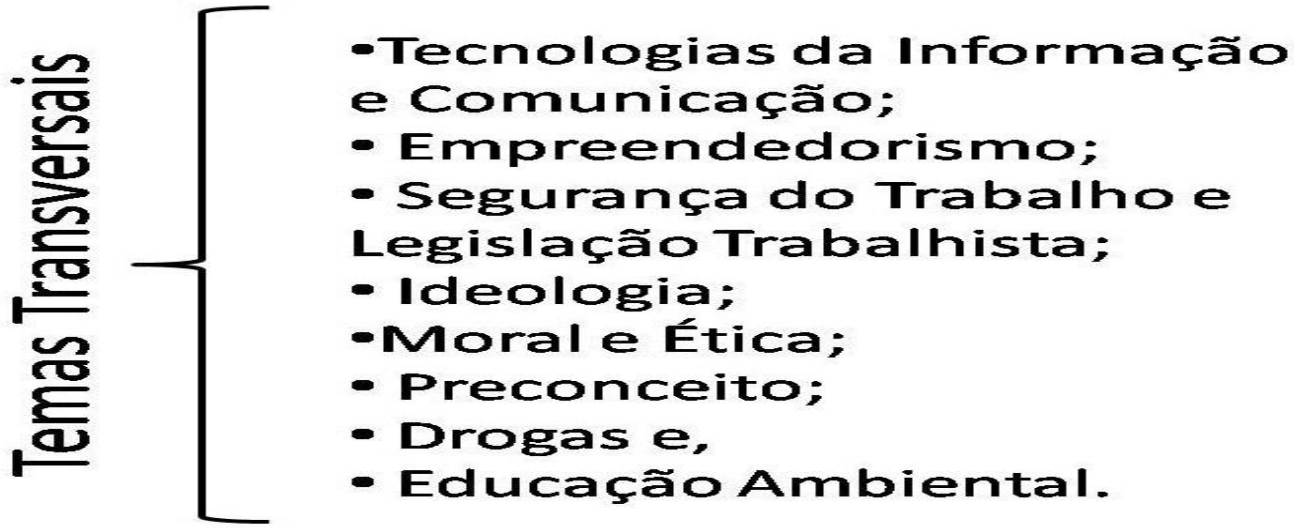

Figura 1 - Temas transversais estudados no programa.

Fonte: Autora.

Para Figueiró (2000, p. 02):

Mesmo que um determinado tema possa ser mais pertinente a uma área do que a outra, o fator decisivo do seu grau de inserção em cada área de conhecimento, poderá depender, pelo menos inicialmente, da afinidade e preparação que o professor tenha em relação ao mesmo.

De acordo com a citação, cabe ressaltar que o educador necessita ter domínio sobre os temas que trabalhará em sala de aula; caso não os possua, precisa empenhar-se para atender a esta nova metodologia de estudo, complementando seus conhecimentos por intermédio de pesquisas, de cursos, de congressos, de palestras etc. É imprescíndivel que esteja preparado para responder às possíveis dúvidas que poderão surgir entre os jovens durante as aulas, visto que o professor tem papel relevante na educação e no processo ensino-aprendizagem.

\subsection{A interdisciplinaridade no programa}

A interdisciplinaridade acontece quando dois ou mais temas/disciplinas são abordados e estudados concomitantemente, sem que ocorra um aprendizado de forma fragmentada. Por meio da interdisciplinaridade, torna-se possível discutir, dentro de um assunto, outros assuntos correlatos que, de alguma maneira, representam parte da cadeia de aprendizagem. Sem dúvida, a postura interdisciplinar implica no desenvolvimento da habilidade de dialogar, de interagir, de produzir conhecimentos de maneira a integrar campos de conhecimentos variados.

Observamos que, nos materiais didáticos estudados durante o programa de aprendizagem, cada tema transversal é abordado separadamente, ou seja, não estão relacionados ou interligados uns com os outros. Também, ficou evidente, durante a observação dos jovens em sala de aula, que a maioria 
deles já tinha conhecimentos sobre o significado do termo interdisciplinaridade; mesmo assim, foi necessária uma prévia explanação sobre o assunto para dar continuidade ao estudo.

Após esta explanação foram distribuídos aos jovens questionários, para que fossem respondidas ${ }^{3}$ algumas indagações sobre o seu perfil, bem como sobre o conhecimento que os mesmos já haviam obtido sobre interdisciplinaridade e transversalidade.

A figura 2 nos mostra o panorama acerca do conhecimento dos jovens em relação à transversalidade, quando questionados se possuíam conhecimento do tema.

- Já ouviu falar em transversalidade? Sim

- Já ouviu falar em transversalidade? Não

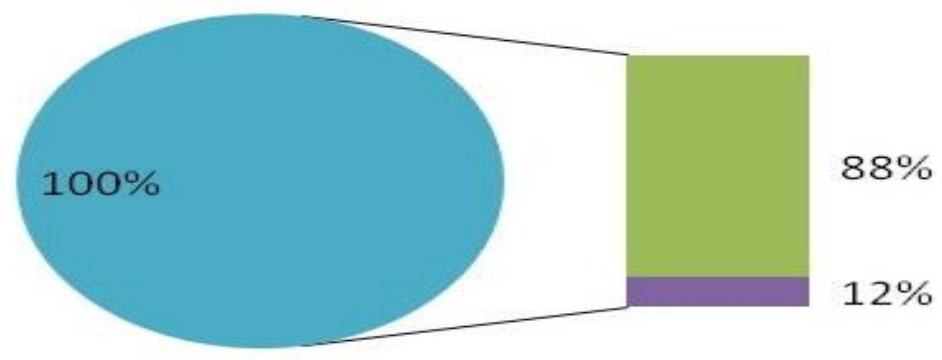

Figura 2 - Conhecimentos dos jovens, matriculados no Programa Jovem Aprendiz, sobre transversalidade

Fonte: autora.

A Figura 3 explica, em porcentagem, a relação dos alunos que já ouviram falar em Interdisciplinaridade. Dessa forma, fica explícito o conhecimento que os jovens já tinham a respeito do tema Interdisciplinaridade.

${ }^{3}$ Os questionários foram respondidos individualmente e sem identificação, tanto do jovem quanto da instituição formadora à qual ele pertence como forma de preservar os jovens e as próprias instituições formadoras. 


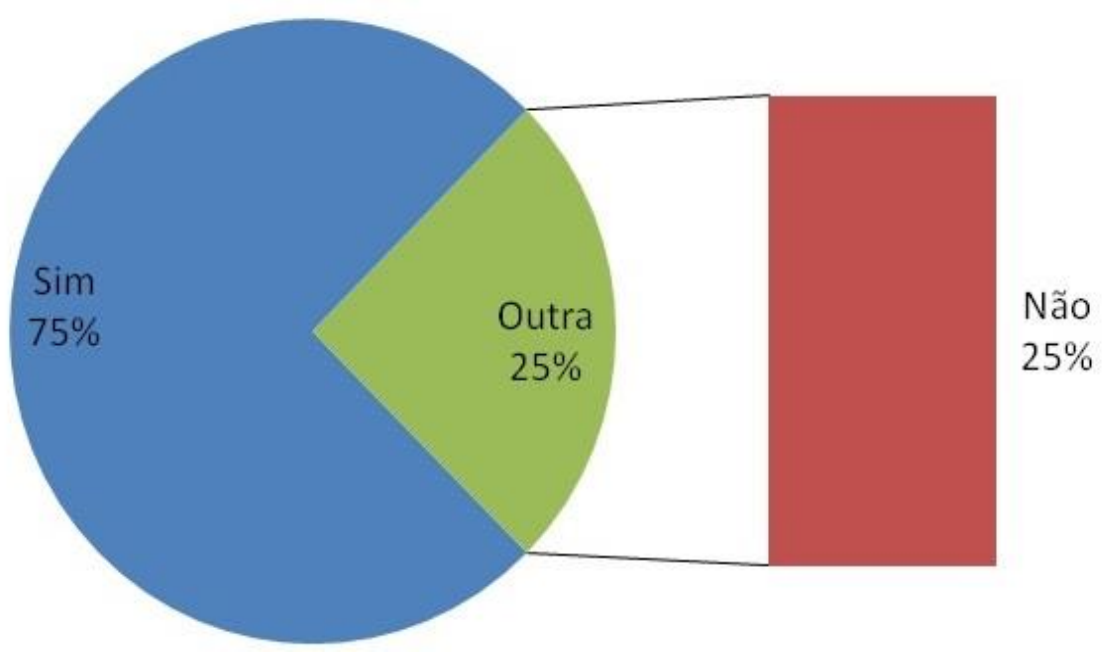

Figura 3 - Percepção dos alunos do Programa Jovem Aprendiz sobre interdisciplinaridade Fonte: autora.

Foi explicado aos jovens que, por intermédio da interdisciplinaridade, é possível que ocorra a integração de conhecimentos de duas mais áreas. Ou seja, podemos estudar diferentes disciplinas, ultrapassando o aprender e o pensar de forma parcial ou fragmentada, quebrando as barreiras do saber disciplinado. Isto é, o saber adquirido disciplina por disciplina acontece, na maioria das vezes, sem o envolvimento ou a interligação de uma disciplina com outra ou com outras. Desse modo, na perspectiva da interdisciplinaridade, o aprendizado não será mais algo isolado, "engavetado", mas com a característica de totalidade, de interconexão entre saberes de disciplinas diferentes.

Segundo Fazenda (2011, p. 69):

A metodologia interdisciplinar em seu exercício requer como pressuposto uma atitude especial ante o conhecimento, que se evidenciam no reconhecimento das competências, incompetências, possibilidades e limites da própria disciplina e de seus agentes, no conhecimento e na valorização suficientes das demais disciplinas e dos que a sustentam.

Os temas exercitados em sala de aula, considerando a apreciação e observância da autora, são todos abordados singularmente, portanto, eles não apresentam ligação interdisciplinar. Com base nisso, questionou-se as instrutoras sobre como as mesmas faziam para tornar suas aulas interdisciplinares, ao que foi explicado que realizavam as atividades, travando diálogos com os jovens sobre os temas, procurando sempre interligar um assunto com o outro, tornando o conhecimento mais amplo e integrado.

Nessa linha de pensamento, Fazenda (2011, p. 86) refere que "[...] numa sala de aula interdisciplinar todos se percebem e gradativamente se tornam parceiros e que nela a interdisciplinaridade pode ser aprendida e pode ser ensinada, o que pressupõe um ato de perceber-se interdisciplinar". No entanto, percebemos que o programa, mesmo não tendo seus conteúdos desenvolvidos interdisciplinarmente, oferece aos jovens estratégias de ensino por meio do trabalho 
interdisciplinar, em que as instrutoras buscam ampliar o horizonte dos aprendizes através de questionamentos, da constante problematização e do diálogo permanente.

De acordo com a Portaria 723/2012, art. 10, parágrafo 1:

As dimensões teóricas e prática da formação do aprendiz devem ser pedagogicamente articuladas entre si, sob a forma de itinerários formativos que possibilitem ao aprendiz o desenvolvimento da sua cidadania, a compreensão das características do mundo do trabalho, dos fundamentos técnico-científicos e das atividades técnico-tecnológicas específicas à ocupação.

É importante ressaltar que o objetivo da interdisciplinaridade é utilizar os conhecimentos de várias disciplinas para compreender um determinado tema, levando em consideração os múltiplos fatores que tecem os diferentes fenômenos e fatos. A interdisciplinaridade favorece a reconstrução de relações entre professores e estudantes; fortalece o diálogo entre teoria e prática; facilita a compreensão da realidade social. Desse modo, uma prática interdisciplinar passa pela necessidade de realizar debates, reflexões, estudos em grupo, socialização de experiências, assegurando a construção de estratégias que permitam a ampliação da mundivisão dos sujeitos envolvidos no ato de ensinar e aprender. É preciso destacar, ainda, que a reconstrução da relação dos docentes com os alunos e com o conhecimento, representa um processo que requer uma nova postura do educador frente ao conhecimento sistematizado e proposto pelos currículos escolares.

A interdisciplinaridade não dilui a disciplina, ao contrário, mantém sua característica individual. Todavia, integra as disciplinas a partir da compreensão das múltiplas causas ou fatores que intervêm sobre a realidade, trabalhando todas as linguagens necessárias para a constituição de conhecimentos, comunicação e negociação de significados e registro sistemático dos resultados (BRASIL, 1999, p. 89).

Por meio do estudo interdisciplinar, o jovem aprendiz tem a possibilidade de ampliar e multiplicar seus conhecimentos. Em se tratando de práticas de aprendizagem, é necessário que diferentes temas sejam trabalhados em sala de aula com a finalidade de proporcionar ao jovem um amplo universo de conhecimentos. Para tanto, uma prática interdisciplinar requer que o trabalho pedagógico seja organizado por meio de pesquisas acerca daquilo que envolve o educando; daquilo que requer respostas, daquilo que gera inquietações.

Na perspectiva escolar, a interdisciplinaridade não tem a pretensão de criar novas disciplinas ou saberes, mas de utilizar os conhecimentos de várias disciplinas para resolver um problema ou compreender um determinado fenômeno sob diferentes pontos de vista. "A interdisciplinaridade tem uma função instrumental. Trata-se de recorrer a um saber diretamente útil e utilizável para resolver às questões e aos problemas sociais contemporâneos" (MEC/PCN's/Ensino Médio, 2002, p. 21). Certamente, a compreensão crítica da totalidade é perpassada por um amplo leque de conhecimentos, que se entrecruzam e se interconectam de maneira interdisciplinar.

Conforme o esquema a seguir, os temas deveriam ser abordados de forma em que houvesse sinergia entre eles, em que todos os tópicos da transversalidade deveriam ser trabalhados de forma harmônica entre si, para que assim se obtenha um estudo interdisciplinar. 


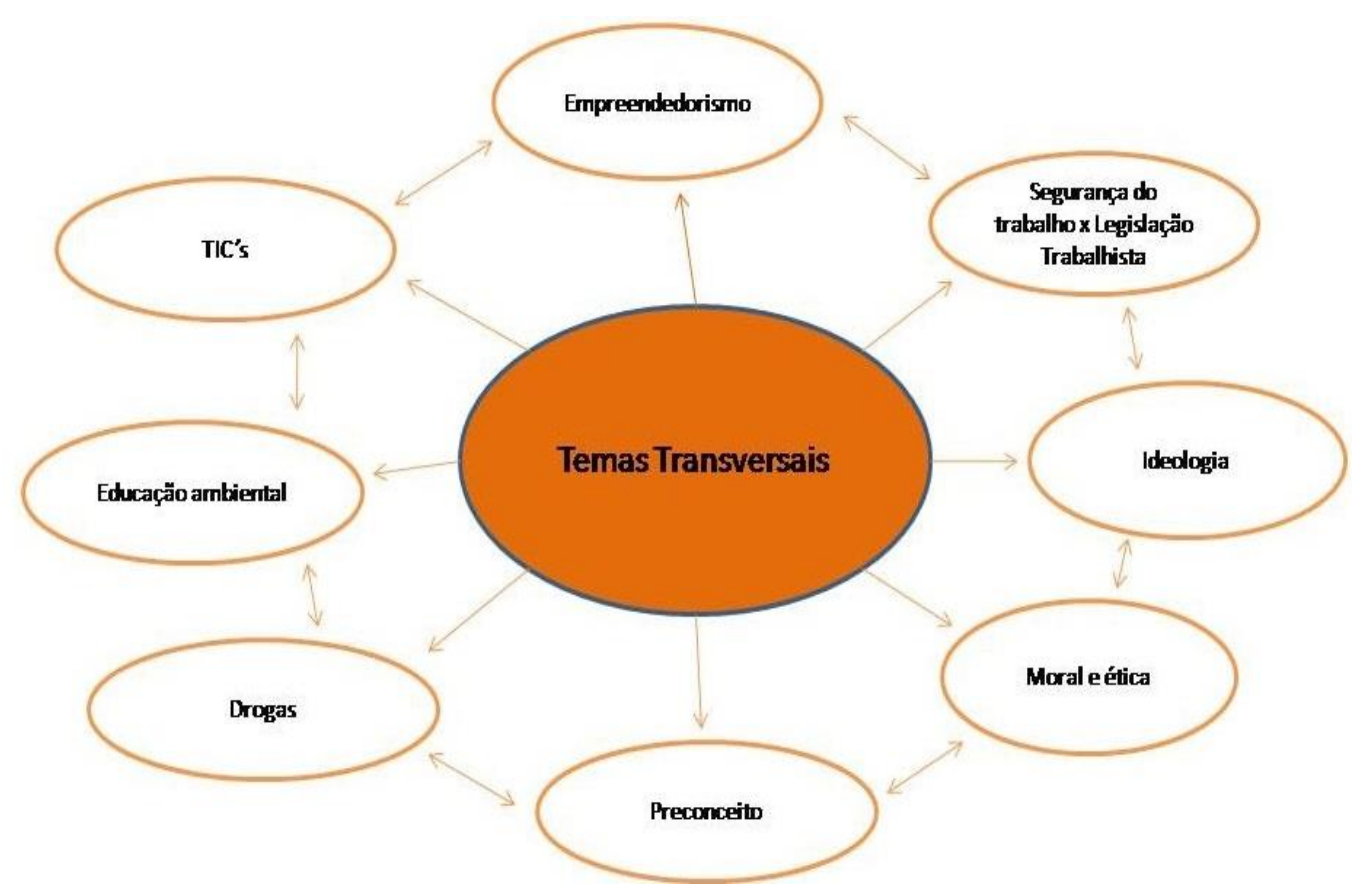

Figura 4 - Tópicos dos Temas Transversais estudados no programa.

Fonte: Autora.

\section{CONSIDERAÇÕES FINAIS}

Sendo o principal objetivo do programa de aprendizagem, a inserção do jovem no mundo do trabalho, muitos deles veem no programa a oportunidade de melhorar de vida. Isso se deve ao fato de que grande parte deste público jovem é oriunda de famílias carentes, ou seja, famílias com baixa renda em que os mesmos sentem a necessidade de começar a trabalhar cedo, para produzir a própria subsistência ou para complementar a renda familiar. Há, também, aqueles que veem no curso a oportunidade de aprimorar-se profissionalmente.

Com esse estudo, observamos que o programa de aprendizagem, em ambas as unidades formadoras, aborda nas suas atividades teóricas os temas transversais, os quais foram investigados durante o estudo, para elaborar este trabalho de conclusão de curso.

Verificamos que são estudadas, além das disciplinas de Língua Portuguesa e Matemática, várias competências transversais, dentre elas Tecnologias da Informação e Comunicação, Empreendedorismo, Segurança do Trabalho e Legislação Trabalhista, Ideologia, Moral e Ética, Preconceito, Drogas e Educação Ambiental. O material didático do programa, em ambas as unidades, é bastante explicativo, permitindo ao jovem aprendiz significativa complementação teórico-prática sobre os assuntos abordados no programa e que são demandados no dia a dia das diversas empresas e no mundo do trabalho.

Contudo, é preciso destacar que a interdisciplinaridade não ocorre por completo; os conteúdos são abordados de modo fragmentado nos encontros semanais realizados por meio do Programa Jovem Aprendiz. Por sua vez, podemos dizer que ocorre a interação das disciplinas durante a capacitação teórica, no momento em que as instrutoras de aprendizagem; nas duas instituições formadoras adotam 
uma proposta interdisciplinar, buscando articular um tema com o outro, isto é, enlaçar vários temas entre si, para tornar as aulas mais produtivas e dinâmicas, buscando romper a barreira do saber fragmentado, do saber disciplinar, do saber em "gavetas".

De acordo com Pinto (1982, p. 20), “[...] quanto mais educado, mais necessita o homem educarse e, portanto, exige mais educação [...]". Assim, a continuidade dos estudos, por intermédio desse curso, faz com que o jovem tenha a oportunidade de ter um futuro melhor, com maior garantia de qualidade de vida, maior segurança e estabilidade profissional. Ainda, o programa serve como complementação escolar para os jovens que estão concluindo seus estudos em escola regular, oferecendo-lhes a possibilidade de ampliarem as suas competências, contribuindo com sua formação escolar, profissional e técnica.

Desse modo, consideramos, mesmo que provisoriamente, que o programa de aprendizagem oferece aos jovens aprendizes a oportunidade de vivenciar e participar de situações coletivas e interdisciplinares durante o seu processo de formação teórica. Sem dúvida, isso auxiliará esse jovem a tornar-se um sujeito consciente e autônomo, capaz de evidenciar a capacidade de tomar iniciativas, de ser um indivíduo mais seguro no processo de aprendizagem, de tomar iniciativas dentro e fora da empresa. Logo, sujeitos aptos a enfrentar as barreiras que os separam do mundo do trabalho e da vida social. A qualificação profissional pode possibilitar a tão sonhada oportunidade de ingressar e de se manter no mercado de trabalho.

\section{Bibliografia}

BONATTO, Andréia et al. Interdisciplinaridade no Ambiente Escolar. Disponível em:

http://www.ucs.br/etc/conferencias/index.php/anpedsul/9anpedsul/paper/ viewFile/2414/501. Acesso: 15 jul. 2015.

BRASIL. Lei № 9.394, DE 20 de dezembro de 1996. Disponível em: http://www.planalto. gov.br/ CIVIL 03/leis/L9394.htm. Acesso: 26 ago. 201

BRASIL. Lei no 10.097, de 19 de dezembro de 2000. Disponível em: http://www. planalto.gov.br/ccivil_03/LEIS/L10097.htm. Acesso: 26 ago. 2015.

BONATTO, Andréia et al. Interdisciplinaridade no Ambiente Escolar. Disponível em: http://www.ucs.br/etc/conferencias/index.php/anpedsul/9anpedsul/paper/ viewFile/2414/501. Acesso: 15 jul. 2015.

BRASIL. Lei № 9.394, DE 20 de dezembro de 1996. Disponível em: http://www.planalto. gov.br/ CIVIL 03/leis/L9394.htm. Acesso: 26 ago. 201

BRASIL. Lei no 10.097, de 19 de dezembro de 2000. Disponível em: http://www. planalto.gov.br/ccivil_03/LEIS/L10097.htm. Acesso: 26 ago. 2015. 
BRASIL. Ministério da Educação. Parâmetros Curriculares Nacionais: Ensino Médio. Brasília: 1999.

BRASIL. Ministério da Educação. Secretaria de Educação Média e Tecnológica. Parâmetros

Curriculares Nacionais: Ensino Médio. Brasília: 2002.

BRASIL. Portaria MTE no- 723, de 23 de abril de 2012 - DOU de 24.04.2012. Disponível em:

http://portal.mte.gov.br/data/files/8A7C816A36A27C140136E58C60

317C60/Portaria\%20MTE\%20n\%C2\%BA723,\%20de\%2023\%20de\%20abril\%20de\%202012.pdf. Acesso:

26 ago. 2015.

CORTELLA, Mario Sergio. A escola e o conhecimento: fundamentos, epistemológicos e políticos. 14. ed. São Paulo: Cortez, 2011.

DEMO, Pedro. Pesquisa: princípio científico e educativo. 14. ed. São Paulo: Cortez, 2011.

FAZENDA, Ivani C. Arantes. Interdisciplinaridade: história, teoria e pesquisa. Campinas, SP: Papirus, 1994. (Coleção Magistério: Formação e Trabalho Pedagógico).

Integração e interdisciplinaridade no ensino brasileiro: efetividade ou ideologia? 5. ed. São

Paulo: Loyola, 2002.

FIGUEIRÓ, Mary Neide Damico. A viabiliadade dos temas transversais à luz da questão do trabalho docente. PSI - Revista de Psicologia Social e Institucional. Disponível em: http://www.uel.br/ccb/psicologia/revista/textov2n12.htm. Acesso: 31 ago. 2015.

HAMZE, Amélia. O princípio da interdisciplinaridade da transversalidade. Disponível em http://educador.brasilescola. com/trabalho-docente/o-principio-da-interdisciplinaridadetransversalida-de.htm. Acesso: 26 ago. 2015.

MUCIDA, Danielle et al. Uma Proposta de Transversalidade na Educação Básica a partir das obras de Viajantes e Naturalistas do Século XIX. Texto acadêmico publicado em 10 de maio de 2012. Revista Vozes dos Vales da UFVJM: Publicações Acadêmicas, MG, Brasil, n. 01, ano I, 05/2012 Reg.: 120.2.095 -2011- PROEXC/UFVJM. Disponível em: http://www.ufvjm.edu.br/vozes. Acesso:21 set. 2015. PINTO, Álvaro Vieira. Sete Lições Sobre Educação de Adultos. São Paulo: Cortez, 1982.

TAHIM, D. O; Santos, M. I. D. de A. Considerações sobre o projeto e-jovem (Seduc/CE) a partir dos conceitos de broadcast e interatividade. Simpósio Internacional de educação a distancia UFSCar. set. 2012. Disponível em: http://sistemas3.sead.ufscar.br/ojs1/index.php/sied/article/view/218/107. Acesso: 02 set. 2015 